\title{
A Study of Sex Differences on Road Crash Severity
}

\author{
Hesamoddin Razi-Ardakani ${ }^{1}$, Amin Ariannezhad ${ }^{2}$, Mohammad Kermanshah ${ }^{1}$ \\ ${ }^{1}$ Sharif University of Technology \\ Azadi Avenue, Tehran, Iran \\ razi@mehr.sharif.ir, mkermanshah@sharif.edu \\ ${ }^{2}$ University of Arizona \\ 1209 E 2nd St. Room 324-G1, Tucson, AZ \\ ariannezhad@email.arizona.edu
}

\begin{abstract}
This study aims to investigate the factors affecting the severity of urban crashes among male and female drives. Traffic crashes occurred in Tehran, Iran during the year 2009 were utilized in this research. The observations were divided into two groups based on driver's gender. Two crash severity models were estimated for each group using binary logit model in which dependent variable included damage only crashes and injury/fatal crashes. Pseudo-elasticity values were calculated to better compare the male and female drivers and understand the exact effect of each variable. The results showed that factors such as increased driver's age, noneducated drivers, weekend, nighttime and intersections have increased the crash severity in both male and female drivers. Among human factors which affect the crash severity, violating the rules, speeding, unnecessary haste and diversion to left, increased the crash severity in males, while lack of driving experience, loss of control and vehicle mechanical defect increased the females' crash severity. Furthermore, accidents involving male drivers were more severe in clear and foggy weather conditions, while female drivers were observed to have more severe crashes in rainy weather. Significant differences in contributing factors to severity of crashes in male and female drivers prove that discrete policies for these two groups of drivers should be adopted. The obtained results suggested that in order to improve the safety of roads and to encourage drivers to obey driving laws, educational programs about males' driving habits should be adopted.
\end{abstract}

Keywords: Crash Severity, Male and Female Drivers, Gender Differences, Binary Logit Model.

\section{Introduction}

The damages inflicted by road crashes have a variety of economic, social, cultural, environmental, health, and mental aspects. Nearly 1.24 million people are killed annually and also tens of millions of people are injured because of road accidents around the world (1). Iran, as a developing country, is confronted with great challenges about road network traffic and road safety. According to the statistics, recent years have been featured with a surge in the number of road crashes, and consequently an increase in life and financial detriment. This induces enormous costs for the country (2). The total quantity of direct and indirect losses resulted from road crashes is estimated to be more than 3\% of Iran's Gross Domestic Products (GDP) (3). During the first half of 2013, 9911 people have died due to road crashes in Iran. Throughout the same period, city of Tehran suffered from 526 casualties (LMO, 2013). This study aims to investigate the effect of various factors on urban crash severity of male and female drivers. The reason behind such a focus on crash severity instead of number and type of crash lies in the paramount importance of understanding the factors leading to higher crash severity and respective injuries sustained by passengers. On the other hand, these factors are not the same among males and females, which heightens the necessity of the study.

Numerous prior studies examined the influences of gender on the frequency, rate, and severity of crashes. The majority of findings indicate that females have experienced more casualty crashes than males (4-12). However, in a study on crash rate in Finland, Massie, et al. (13) concluded that severe and fatal crashes are more probable for male drivers than female ones. Similarly, Li, et al. (14) study on crash results for 10000 drivers revealed a triple fatality ratio for males compared to females. Moreover, the overall rate of accidents was also found to be higher for male drivers (15-18) and played a more dominant role in accidents. $(15,17,19)$. Careless driving and impatience behavior during driving among male drivers as well as less offences and better law abidance among females could be the reasons for a lower accident ratio for females $(19,20)$. Risky behaviors and neglecting laws and regulations lead to higher accident frequency among 
males (21-23). Harré, et al. (24) stated that young male drivers have considerably more risky behaviors than young females. In comparison with females, risky driving habits among male drivers play a major role in fatal loss-of-control crashes (25). Laapotti and Keskinen (26) declared that aggressive behaviors are more prevalent among male drivers than females, which stayed constant in Finland during 1984-2000.

Investigating the effects of gender on accidents among motorcyclists, Chang and Yeh (27) showed that male drivers are by far more likely to infringe law. In contrast to males' risky behaviors, females' cautious and safe driving behaviors are ascertained in studies like $(14,28,29)$.

In addition to these reckless and risky behaviors in male drivers, lack of driving experience among females is pointed as the reason behind accidents in various studies. Li, et al. (14) asserted that despite lower fatal crashes, females did not deliver safer performance than males in similar conditions. Laapotti and Keskinen (25) maintained that inadequacy of vehicle handling skills among females was a critical cause of fatal crashes and Chang and Yeh (27) stated that less competency and experience in motorcycle driving, as a cause for accidents, was more probable in females. In high speeds, female drivers are more likely than males to apply incorrect maneuvers (30) and in lane changing tests; males have proved to be more skilled lane changers (31). Based on the official national statistics of Sweden, females are better in written driving tests, whereas males display better practical results (32).

Multiple studies on differences among male and female drivers have also considered age as well as gender effects in examining the crash rate $(4,13,33)$, the crash rate due to losing vehicle control $(34)$, drivers' responsibility in fatal crashes (35), committing traffic offences during driving (15), crash types (36), and driving patterns of old drivers (37). Williams and Shabanova (35) declared that young male drivers are more responsible in fatal crashes than female ones. Nonetheless, female drivers of over 50 years of age are more likely to be responsible in fatal crashes than male drivers of the same age. Bingham and Ehsani (36) pointed out that young male drivers are more liable to be in single-vehicle and fatal head-on crashes while left- and right-side crashes are more prevalent among females. A study by Karacasu and Er (15) presented some differences in committing offences and their types between male and female drivers. Males are more inclined to violate passing priorities at intersections, whereas females mostly collide with rear side of vehicles.

There is a paucity of research concerned with the effects of sex on influencing the crash severity. Ulfarsson and Mannering (21) investigated the differences between males and females regarding injury severity in road crashes using multinomial Logit model. The results revealed that some injuries, such as those caused by striking barriers or guardrails resulted in crash severity based on the gender. In addition, a wide range of behavioral and psychological differences were observed between males and females, which need to be taken into account in designing roads and cars. Islam and Mannering (38) adopted the same model to survey the severity of injuries sustained by male and female drivers owing to single-vehicle crashes in India. Their findings revealed a considerable difference in factors affecting crash severity between males and females. Another study was conducted by Obeng (39) that mainly addressed the role of gender in crash severity occurred at signalized intersection. The author utilized the ordered Logit model and identified major differences in crash severity on factors such as driver condition, seatbelt use, and air bag deployment based on gender. Consequently, it was concluded that in order to achieve appropriate results, separate models should be estimated for males and females.

Investigating the factors associated with car accidents based on gender differences has recently gained momentum in Iran while no solid investigation has been conducted in this issue yet. Perceiving the behavioral, skill, and psychological differences between males and females can be influential in national transportation policy making toward raising the safety standards. This study aims to identify the factors affecting the severity of urban crashes among males and females by utilizing the large numbers of explanatory variables. For this purpose, two separate binary logit models have been developed and effective factors on crash severity of each sex group have been determined.

As it was mentioned, through the studies in the literature, investigation of the factors affecting the crash severity of males and females has been the main objective of only few of them which have been carried out using the database of the developed country of USA. Considering that the crash database of the developing country of Iran has been utilized in this study, the results could be considered as a pattern for developing counties and improve the literature of this issue. Furthermore, utilizing the large number of explanatory variables (e.g., environmental, roadway, crash and driver characteristics) in order to better understand the differences in males' and females' behaviors and driving patterns is another remarkable feature of this study. 


\section{Methodology}

In order to study crash severity, the sample data is classified into two categories based on the driver's gender. The factors affecting the crash severity are determined with the binary Logit model for each class of data independently. Logit is the most prominent type of discrete choice models (40) which are derived from economic theory of random utility (41). In such models it is assumed that decision makers choose among a set of discrete alternatives based on the alternatives utility which is due to the properties of both the actual alternatives and the decision maker. In crash severity modeling, alternative utility is defined as a function of factors affecting crash severity. The binary type of logit model is used where prediction of occurrence probability for two discrete outcomes is investigated. In this study, the two examined outcomes are damage-only crashes and injury/fatal crashes. Utility is defined as below function (42):

$$
U_{n i}=V_{n i}+\varepsilon_{n i}
$$

where, Uni is the utility of severity level $\mathrm{i}$ (discrete outcome i) for accident $\mathrm{n}$, Vni is the measurable part of utility at severity level $\mathrm{i}$ for accident $\mathrm{n}$, and $\varepsilon_{\text {in }}$ is disturbance term (the unobservable part of utility at severity level $\mathrm{i}$ for accident $\mathrm{n}$ ). In the case where two severity levels are defined for an accident, severity level 1 is observed in accident $n$ only when the utility function of this outcome is higher than utility for severity level 2. In other words:

$$
U_{n 1} \geq U_{n 2}
$$

Measurable term of utility function, Vi, is defined as follow:

$$
V_{i}=\alpha_{i}+\beta_{1 i} X_{1 i}+\beta_{2 i} X_{2 i}+\beta_{3 i} X_{2 i}+\ldots+\beta_{n i} X_{n i}
$$

where, $\mathrm{Vi}$ is the utility of outcome $\mathrm{i}, \alpha_{i}$ is constant of equation (property of outcome $\mathrm{i}$ ), $\mathrm{Xji}$ is the jth characteristics of outcome $\mathrm{i}$ and $\beta_{j i}$ is the parameter to be estimated for discrete outcome i. Therefore, probability of observing severity level 1 for the accident $\mathrm{n}, \mathrm{Pn} 1$, is:

$$
P_{n 1}=P\left(U_{n 1} \geq U_{n 2}\right)=P\left(V_{n 1}-V_{n 2} \geq \varepsilon_{n 2}-\varepsilon_{n 1}\right)
$$

and for severity level 2 for accident $n$ is expressed as:

$$
P_{n 2}=1-P_{n 1}
$$

By assuming a distribution of random disturbance term, $\varepsilon$, the following two popular estimable models can be developed: Logit and Probit. When the disturbance term $\varepsilon$ in equation (4) is assumed to have Gumbel distribution, the subtraction of two gumbel variates is logistic distributed and thus, results in binary Logit model. Due to the closed form of integral for Logit model, the probability of binary Logit model is written as:

$$
\begin{aligned}
& P_{n 1}=\frac{e^{U_{n 1}}}{e^{U_{n 1}}+e^{U_{n 2}}} \\
& P_{n 2}=\frac{e^{U_{n 2}}}{e^{U_{n 1}}+e^{U_{n 2}}}
\end{aligned}
$$

The parameter vector $\beta$ in Logit and Probit model is estimated using standard maximum likelihood method. This method is 
based on maximizing the probability of simultaneous occurrence of the observations. The likelihood function is defined as:

$$
L(\beta)=\prod_{n=1}^{N} \prod_{i}\left(P_{n i}\right)^{y_{n i}}
$$

where $\mathrm{N}$ is the total number of observations. If the observed discrete outcome for observation $\mathrm{n}$ is $\mathrm{i}$, then $y_{n i}$ is equal to one, and zero otherwise. The log likelihood function from equation (8) is written in equation (9) and should be maximized in order to estimate coefficient $\beta$.

$$
L L(\beta)=\sum_{n=1}^{N} \sum_{i} y_{n i} \ln P_{n i}
$$

Goodness of fit statistic, $\rho^{2}$, is a common measure of overall model fit (40). $\rho^{2}$ is defined for the models that are developed through maximum likelihood method (e.g. Logit model), as follows:

$$
\rho^{2}=1-\frac{L L(\beta)}{L L(0)}
$$

where $\operatorname{LL}(\beta)$ is the $\log$ likelihood at the point of convergence with estimated coefficients $\beta$ and $\operatorname{LL}(0)$ is the initial log likelihood with all coefficients equal to zero. The $\rho^{2}$ statistic varies between zero and one, where values close to one represent better prediction of model.

The statistical significance of estimated coefficients in binary Logit model is assessed using t-test. For this purpose, if null hypothesis for specified coefficient is rejected, it means that the coefficient is significantly different from zero.

Consequently, a variable is assumed to be affecting crash severity if estimated coefficient of that variable is statistically significant at $90 \%$ confidence interval. In addition, one of the main features of this model is to assure that multicollinearity between the descriptive variables does not occur, since the variance factor of the coefficient tends to infinity if multicollinearity between the independent variables exists. Therefore, variance inflation factor is used to distinguish multicollinearity between the descriptive variables (43). This factor is calculated for each variable as follows:

$$
V I F_{j}=\frac{1}{1-R_{j}^{2}}
$$

where, $R_{j}^{2}$ refers to the model in which variable $\mathrm{j}$ is the dependent variable and other descriptive variables are independent. When value of this factor for a specific variable reaches above 5multicollinearity between that variable and others occurs.

Since the values of variable coefficients do not fully explain the effect of variables on the probability of observing each alternative, an elasticity parameter is usually utilized to explain the results. For binary variables, pseudo-elasticity parameter is calculated. Since the above variables can only take zero and one, a $1 \%$ change in their values is not defined and as a result, the change in the probability of observance of each alternative is determined based on the change in the value of each variable from zero to one. The pseudo-elasticity parameter is calculated as follows:

$$
E_{x_{k j}}^{P_{j}}=\frac{P_{j}\left[x_{k j}=1\right]-P_{j}\left[x_{k j}=0\right]}{P_{k j}\left[x_{k j}=0\right]}
$$

To further improve the accuracy of this parameter, an average value of the pseudo-elasticity parameter over a range of observations should be calculated (44). 


\section{Data Description}

Urban car accidents which occurred in 2009 in Tehran have been investigated in this research. This information is obtained through traffic police database which has been prepared through collecting completed forms of K114 concerning registered accidents. K114 forms are completed at the scene of the accident by traffic experts who are responsible for investigating accidents and hence, record all information regarding all occurred accidents in Iran in addition to their causes. These data are constituted of 5 main parts consisting properties of the vehicles involved in accident, drivers characteristics, road characteristics, information regarding the circumstances in which the accident took place and quality of driving and instruction rules observance.

Information prepared through police databases was obtained in two separate databases in Microsoft access software, one database including information regarding the accident and the other containing drivers characteristics involved in the accident. In order to prepare the required data, the two mentioned databases were combined in MATLAB software upon the base of serial numbers and series as the indicator of each observation. Obtained data containing each accident characteristics accompanied by driver or drivers characteristics involved are considered as final prepared data.

Incomplete observations and the cases in which part of the required information was missing were omitted. Moreover, after excluding the accidents in which pedestrians or motorcycles were involved, 13695 crashes were ultimately examined. Table 1 presents descriptive statistics for the data categorized by male and female drivers. Table 1 indicates that females were only involved in $11 \%$ of the accidents, whereas males were involved in $89 \%$ of the accidents. The dependent variable of model is crash severity which is defined as binary outcome (damage only and injury/fatal). Under this classification, the fatal crashes which constituted only a small portion of the whole study sample, were categorized as injury crashes. In this manner among male drivers, damage and injury/fatal crashes respectively constitute $92.2 \%$ and $7.8 \%$ of all accidents data. Female drivers' accidents consist of $92 \%$ damage crashes and $8 \%$ injury/fatal crashes.

The factors under study embody a wide range of variables such as driver specification (age, education level), date and time of accident (weekday or weekend), environmental factors (weather and light), traffic conditions (traffic volume, road type and road width), and crash characteristics (collision type and effective driver faults).

Table 1: Sample Characteristics.

\begin{tabular}{|c|c|c|}
\hline Variable & Males & Females \\
\hline \multicolumn{3}{|l|}{ Driver age } \\
\hline Up to 25 & $30.6 \%$ & $35.9 \%$ \\
\hline $26-49$ & $68.3 \%$ & $62.6 \%$ \\
\hline 50 above & $1.2 \%$ & $1.5 \%$ \\
\hline \multicolumn{3}{|l|}{ Driver's education } \\
\hline Illiterate & $4.4 \%$ & $4.0 \%$ \\
\hline Below high school diploma & $83.0 \%$ & $76.7 \%$ \\
\hline High school diploma and above & $12.6 \%$ & $19.3 \%$ \\
\hline \multicolumn{3}{|l|}{ Human Factor } \\
\hline Fatigue and Sleepy & $0.5 \%$ & $0.6 \%$ \\
\hline Violating the rules & $19.0 \%$ & $11.1 \%$ \\
\hline Unnecessary haste & $14.2 \%$ & $7.9 \%$ \\
\hline Unsafe longitudinal distance & $27.5 \%$ & $18.4 \%$ \\
\hline Unsafe lateral distance & $5.9 \%$ & $4.6 \%$ \\
\hline Disregarding right of way rules & $13.8 \%$ & $11.3 \%$ \\
\hline Inattention to road & $15.6 \%$ & $13.6 \%$ \\
\hline lack of driving experience & $5.5 \%$ & $8.9 \%$ \\
\hline Loss of control & $1.8 \%$ & $4.9 \%$ \\
\hline Speeding & $18.5 \%$ & $7.7 \%$ \\
\hline diversion to left & $1.4 \%$ & $0.8 \%$ \\
\hline Vehicle Mechanical defect & $2.2 \%$ & $2.8 \%$ \\
\hline Running red light & $0.8 \%$ & $1.1 \%$ \\
\hline \multicolumn{3}{|l|}{ Days of week } \\
\hline Weekend & $5.9 \%$ & $6.3 \%$ \\
\hline Weekday & $94.1 \%$ & $93.7 \%$ \\
\hline \multicolumn{3}{|l|}{ Crash hour } \\
\hline Peak hour & $15.7 \%$ & $8.1 \%$ \\
\hline
\end{tabular}




\begin{tabular}{|c|c|c|}
\hline Variable & Males & Females \\
\hline Off-peak hour & $84.3 \%$ & $91.9 \%$ \\
\hline \multicolumn{3}{|l|}{ Light condition } \\
\hline Daytime & $86.6 \%$ & $82.2 \%$ \\
\hline Nighttime & $13.4 \%$ & $17.8 \%$ \\
\hline \multicolumn{3}{|l|}{ Weather condition } \\
\hline Clear & $94.7 \%$ & $91.1 \%$ \\
\hline Foggy & $0.4 \%$ & $0.6 \%$ \\
\hline Snowy & $0.1 \%$ & $0.3 \%$ \\
\hline Rainy & $2.7 \%$ & $4.1 \%$ \\
\hline Others & $2.1 \%$ & $3.9 \%$ \\
\hline \multicolumn{3}{|l|}{ Traffic Volume } \\
\hline less than $2000 \mathrm{VPH}$ & $38.4 \%$ & $24.4 \%$ \\
\hline $2000-6000$ & $6.5 \%$ & $8.3 \%$ \\
\hline $6000 \mathrm{VPH}$ and above & $55.1 \%$ & $67.3 \%$ \\
\hline \multicolumn{3}{|l|}{ Roadway type } \\
\hline Intersection & $10.7 \%$ & $12.2 \%$ \\
\hline Bridge & $1.0 \%$ & $0.4 \%$ \\
\hline Roundabout & $0.3 \%$ & $0.6 \%$ \\
\hline Highway & $20.4 \%$ & $22.3 \%$ \\
\hline Others types & $67.6 \%$ & $64.5 \%$ \\
\hline \multicolumn{3}{|l|}{ Road width } \\
\hline Up to 18 meters & $25.8 \%$ & $33.9 \%$ \\
\hline $19-24$ & $23.0 \%$ & $19.2 \%$ \\
\hline 25 meters above & $51.2 \%$ & $46.9 \%$ \\
\hline \multicolumn{3}{|l|}{ Surface condition } \\
\hline Dry & $88.3 \%$ & $87.5 \%$ \\
\hline Wet & $3.4 \%$ & $5.1 \%$ \\
\hline Icy or snowy & $0.8 \%$ & $0.6 \%$ \\
\hline Other types & $7.5 \%$ & $6.8 \%$ \\
\hline \multicolumn{3}{|l|}{ Crash Type } \\
\hline Hit fixed object & $9.3 \%$ & $12.4 \%$ \\
\hline Rollover & $1.3 \%$ & $1.9 \%$ \\
\hline Multivehicle & $5.2 \%$ & $6.8 \%$ \\
\hline Other types & $84.2 \%$ & $78.9 \%$ \\
\hline \multicolumn{3}{|l|}{ Collision Type } \\
\hline Head on & $2.9 \%$ & $2.4 \%$ \\
\hline Rear end & $60.3 \%$ & $55.6 \%$ \\
\hline Angle & $19.1 \%$ & $19.2 \%$ \\
\hline Sideswipe & $11.4 \%$ & $13.9 \%$ \\
\hline Other types & $6.3 \%$ & $8.9 \%$ \\
\hline
\end{tabular}

\section{Modeling and Results}

The obtained data was divided into two groups: male and female drivers. After being prepared for the modeling process the following steps were taken on each group separately. Variables with a high correlation were excluded using a correlation matrix. To limit the number of variables, parameters affecting the crash severity were distinguished via the ChiSquared independence test. It is worth mentioning that variables were retained if they were significant at least at the 0.1 level according to the t-statistics of their estimated coefficients. The final model was selected after considering different combinations of the variables. The Stata (45) and NLOGIT Statistical software (42) were utilized in this process.

Table 2 shows males' and females' crash severity estimation results. The difference between the factors affecting the crash severity among males and females is comprehendible through a comparison of coefficients in males and females models, where the value of coefficients for a variable has a direct relationship with the possibility of injury crashes for that particular variable. The goodness of fit coefficient was determined to be 0.233 for the model developed for male drivers and 0.306 for females which ascertains the high capability of these models for estimating observations. Variance inflation factors (VIF) were estimated for all independent variables and were found to be below 5 , which indicated the lack of collinearity among the final variables. 
Table 2: Males' and Females' Crash Severity Estimation Results.

\begin{tabular}{|c|c|c|c|c|}
\hline \multirow{2}{*}{ Variable } & \multicolumn{2}{|c|}{ Males } & \multicolumn{2}{|c|}{ Female } \\
\hline & Coefficient & $\mathrm{t}$ & Coefficient & $\mathrm{t}$ \\
\hline \multicolumn{5}{|l|}{ Driver age } \\
\hline Up to 25 & $0.172 * *$ & 2.09 & $0.622 * * *$ & 2.74 \\
\hline 50 and above & $1.847 * * *$ & 8.07 & $2.370 * * *$ & 4.48 \\
\hline \multicolumn{5}{|l|}{ Driver's education } \\
\hline Illiterate & $0.168 * *$ & 2.11 & $0.349 *$ & 1.84 \\
\hline \multicolumn{5}{|l|}{ Human Factor } \\
\hline Violating the rules & $1.904 * * *$ & 6.63 & - & - \\
\hline Unnecessary haste & $0.566 * * *$ & 2.90 & - & - \\
\hline Unsafe longitudinal distance & $-0.697 * * *$ & -6.85 & $-0.467 * *$ & -2.51 \\
\hline Unsafe lateral distance & $-0.632 * * *$ & -2.58 & $-1.550^{* * *}$ & -2.70 \\
\hline lack of driving experience & - & - & $1.186^{* * *}$ & 5.98 \\
\hline Loss of control & - & - & $0.973 * * *$ & 3.77 \\
\hline Speeding & $0.847 * * *$ & 3.72 & - & - \\
\hline Diversion to left & $0.582 * *$ & 2.09 & - & - \\
\hline Vehicle Mechanical defect & $-0.768 * * *$ & -3.74 & $1.754 * *$ & 2.08 \\
\hline \multicolumn{5}{|l|}{ Days of week } \\
\hline Weekend & $2.486 * * *$ & 3.09 & $0.589 * *$ & 2.05 \\
\hline \multicolumn{5}{|l|}{ Crash hour } \\
\hline Peak hour & $-0.516^{*}$ & -1.80 & $-0.164 * *$ & -2.26 \\
\hline \multicolumn{5}{|l|}{ Light condition } \\
\hline Nighttime & $0.380 * * *$ & 3.64 & $0.653 * *$ & 2.56 \\
\hline \multicolumn{5}{|l|}{ Weather condition } \\
\hline Clear & $0.810 * * *$ & 3.01 & $-0.608^{* *}$ & -2.50 \\
\hline Foggy & $1.820 * * *$ & 5.09 & - & - \\
\hline Rainy & - & - & $0.200^{*}$ & 1.76 \\
\hline \multicolumn{5}{|l|}{ Traffic Volume } \\
\hline less than $2000 \mathrm{VPH}$ & $1.995 * *$ & 2.31 & $0.820 * * *$ & 2.82 \\
\hline \multicolumn{5}{|l|}{ Roadway type } \\
\hline Intersection & $1.948 * * *$ & 11.01 & $0.014^{*}$ & 1.91 \\
\hline Bridge & $-0.826^{* *}$ & -2.37 & - & - \\
\hline Highway & - & - & $0.973 * * *$ & 3.77 \\
\hline \multicolumn{5}{|l|}{ Road width } \\
\hline Up to 18 meters & $0.349 * *$ & 2.30 & $0.784 * *$ & 2.18 \\
\hline 25 meters and above & $0.221 *$ & 1.78 & $-0.319 * *$ & -2.05 \\
\hline \multicolumn{5}{|l|}{ Crash Type } \\
\hline Hit fixed object & $0.855 * * *$ & 3.70 & $-0.387 *$ & -1.91 \\
\hline Rollover & $0.415 * *$ & 2.29 & - & - \\
\hline Multivehicle & $0.656 * * *$ & 6.11 & $-0.873^{* * *}$ & -2.89 \\
\hline \multicolumn{5}{|l|}{ Collision Type } \\
\hline Head on & $0.928 * * *$ & 5.27 & - & - \\
\hline Angle & $0.468 * * *$ & 4.02 & - & - \\
\hline Sideswipe & $-0.556 * * *$ & -3.24 & - & - \\
\hline constant & $-2.884 * * *$ & -8.29 & $-3.845 * * *$ & -6.68 \\
\hline \multicolumn{5}{|l|}{ Model } \\
\hline Observations & 12,293 & & 1,400 & \\
\hline Logliklihood at start & -3354.53 & & -390.28 & \\
\hline Logliklihood at convergence & -2574.14 & & -270.70 & \\
\hline$\rho^{2}$ & 0.233 & & 0.306 & \\
\hline
\end{tabular}




\section{Discussion}

The investigated parameters have been analyzed based on the estimation results of the two models. The elasticity values for variables in both models were calculated and are presented in Table 3 in order to examine the crash severity differences between male and female drivers.

The elasticity denotes the amount of change in possibility of increasing the accident severity due to a change in relative descriptive variables. The following results represent the analysis of model coefficients and their elasticity values. Consistent with previous finding (46) this study confirms that the ages under 25 in both models have a positive coefficient which indicates higher possibility of severe crashes for drivers under 25 in both groups (males or females, where young females lead to a higher increase in severe crashes ( $77.1 \%$ for females against $17.2 \%$ for males). The age group of over 50 also raises the possibility of injury accident. It is worth mentioning that in both sexes, older drivers are more prone to severe crashes than younger ones (395.5\% for males and $600.4 \%$ for females). Similar conclusions were drawn by numerous studies (47-53). The coefficients of driver age variables attest a U-type relation between age and severity of accident, which corresponds with other studies (54).

Illiteracy of drivers in both groups resulted in more severe accidents. Though the percentage of illiterate drivers was low, it exerted a similar effect on crash severity among both males and females (16.8\% for males and $37.5 \%$ for females).

In order to probe the driver errors involved in the crashes, 13 factors were used as independent variables in the model estimating process. Variables of lack of driving experience and loss of vehicle control in female drivers, whereas violation, unnecessary haste, and speeding in male drivers were found to lead to more severe crashes. It has been revealed in a past study that males are inclined to be more adventurous and drive at higher speeds compared to females $(21,55)$. In previous studies $(21,38,56-60)$ without considering gender differences, authors found that speeding significantly increases crash severity for all drivers. It can be concluded that females are less skillful drivers than males, which increases the severity of their accidents which conforms to other similar studies $(14,25,27)$. The results also prove males to exhibit more risky driving behaviors and to be less compliant with traffic regulations, which is consistent with other researches on drivers in Tehran (61) and other countries (21-27).

Accidents caused by unsafe longitudinal and lateral distance from other vehicles resulted in lower severity for both groups. These findings may be due to the nature of such collision types which generally occur at lower speeds and heavy traffic, and consequently often lead to property damage. Previous research (21) has shown that following too closely significantly decreases injury severity among males. Additionally, an interesting result was achieved in accidents caused by vehicle mechanical defects. Mechanical defects increased the possibility of non-injury accidents in males by $100.4 \%$, whereas they raised the possibility of injury crashes among females by $346.9 \%$. This could be because of females' unfamiliarity with the mechanical issues which leads to their inability to recognize defects and make the correct decision at proper time (either before or at the time of crash). Diversion to left is another factor which influences the severity of accidents for males and increases the probability of fatalities/injuries by $69.7 \%$. Results indicate that in comparison with other factors, violation was more influential in accident severity among male drivers by a rate of $417.9 \%$.

Occurrence of a crash on weekends increases the likelihood of injuries among males and females, by $190.5 \%$ and $70.9 \%$, respectively. This may be due to the increased indiscretion of drivers on vacation trips. Low traffic volume on weekends and males' tendency for driving at high speeds could be the factors incurring severe crashes among males. Similar conclusions were drawn by (62-65).

Both males and females groups had similar results in terms of the time of accidents; crashes in peak periods tend to be less severe for both males and females, which seems to be logical due to slower driving traffic caused by the rush-hour traffic. Similar result was observed in other studies as well $(21,48,51,64-66)$. 
Table 3 Average Pseudo-Elasticities Of The Variables Affecting Males’ And Females' Crash Severity.

\begin{tabular}{|c|c|c|}
\hline \multirow{2}{*}{ Variable: } & \multicolumn{2}{|c|}{ Model Elasticities } \\
\hline & Males & Females \\
\hline \multicolumn{3}{|l|}{ Driver age } \\
\hline Up to 25 & $17.2 \%$ & $77.1 \%$ \\
\hline 50 and above & $395.5 \%$ & $600.4 \%$ \\
\hline \multicolumn{3}{|l|}{ Driver's education } \\
\hline Illiterate & $16.8 \%$ & $37.5 \%$ \\
\hline \multicolumn{3}{|l|}{ Human Factor } \\
\hline Violating the rules & $417.9 \%$ & - \\
\hline Unnecessary haste & $68.4 \%$ & - \\
\hline Unsafe longitudinal distance & $-47.5 \%$ & $-35.1 \%$ \\
\hline Unsafe lateral distance & $-44.6 \%$ & $-77.1 \%$ \\
\hline lack of driving experience & - & $188.3 \%$ \\
\hline Loss of control & - & $141.7 \%$ \\
\hline Speeding & $114.9 \%$ & - \\
\hline diversion to left & $69.7 \%$ & - \\
\hline Vehicle Mechanical defect & $-100.4 \%$ & $346.9 \%$ \\
\hline \multicolumn{3}{|l|}{ Days of week } \\
\hline Weekend & $190.5 \%$ & $70.9 \%$ \\
\hline \multicolumn{3}{|l|}{ Crash hour } \\
\hline Peak hour & $-61.9 \%$ & $-14.0 \%$ \\
\hline \multicolumn{3}{|l|}{ Light condition } \\
\hline Nighttime & $41.7 \%$ & $83.3 \%$ \\
\hline \multicolumn{3}{|l|}{ Weather condition } \\
\hline Clear & $107.9 \%$ & $-42.1 \%$ \\
\hline Foggy & $384.0 \%$ & - \\
\hline Rainy & - & $20.1 \%$ \\
\hline \multicolumn{3}{|l|}{ Traffic Volume } \\
\hline less than $2000 \mathrm{VPH}$ & $434.8 \%$ & $110.7 \%$ \\
\hline \multicolumn{3}{|l|}{ Roadway type } \\
\hline Intersection & $84.0 \%$ & $1.2 \%$ \\
\hline Bridge & $-53.8 \%$ & - \\
\hline Highway & - & $141.7 \%$ \\
\hline \multicolumn{3}{|l|}{ Road width } \\
\hline Up to 18 meters & $37.7 \%$ & $102.2 \%$ \\
\hline 25 meters above & $18.5 \%$ & $-33.8 \%$ \\
\hline \multicolumn{3}{|l|}{ Crash Type } \\
\hline Hit fixed object & $116.2 \%$ & $-42.2 \%$ \\
\hline Rollover & $46.1 \%$ & - \\
\hline Multivehicle & $81.9 \%$ & $-119.4 \%$ \\
\hline \multicolumn{3}{|l|}{ Collision Type } \\
\hline Head on & $130.8 \%$ & - \\
\hline Angle & $53.6 \%$ & - \\
\hline Sideswipe & $-40.4 \%$ & - \\
\hline
\end{tabular}

Accidents are more likely to be severe at nights which are more probable for females, such that the probability of fatalities/injuries was increased by $83.3 \%$ for females and $41.7 \%$ for males. Drivers generally have limited sight and more reaction time at nights, leading to more severe accidents at nights in comparison with daylight. This finding corroborates earlier observations by $(49,60,67-69)$.

Analysis of weather conditions indicate that clear weather decrease the crash severity for females, whereas this factor was found to increase the severity among males. Previous researches have reported conflicting results on the effect of clear 
weather condition on crash severity. Some studies by $(52,59,70)$ found that clear weather is associated with increased severity, while $(51,66,69)$ have concluded the opposite. Accordingly, it can be inferred that higher speeds for males and more careful driving for females in such conditions are the reasons for the mentioned results. Good weather conditions are associated with imprudence among males as well. Consistent with previous finding by (21), it is proved that foggy weather is associated with higher males crash severity. Results also show that rain increases the severity of accidents among females. Poorer driving skills in females, particularly in adverse conditions could be the reason here.

For both genders, accidents in volume less than 2000 vehicles per hour are more probable to be severe. This possibility is higher for males, owing to more careless driving and risky behaviors ( $434.8 \%$ for males against $110.7 \%$ for females). In general, lower traffic volume results in higher vehicles' speed and more probability of incurring severe accidents maneuvers.

With regard to the type of roads, this study determined that accidents which occur at intersections tend to be more severe for both males and females which was consistent with findings of other studies $(38,46,58,71)$. This factor increases the probability of injuries/fatalities among males and females groups, by $84.0 \%$ and $1.2 \%$, respectively. In this case, the possibilities of more severe accidents are higher for males which may be due to their incautious driving at these places. Males are less likely to experience severe accidents on bridges, which is most probably due to their better skills of controlling the vehicle in such places. Females' crashes in highways are associated with greater severity; less experience and skill in controlling the vehicle at high speeds could be a reason for this finding.

The road width of up to 18 meters increases the possibility of injury accidents as compared with width of 18-25 meters in both groups. Results reveal that females are more prone to severe accidents in narrow roads than males (37.7\% for males against $102.2 \%$ for females). Roads with 25 meters width and above increase the possibility of severe accidents for males by $33.8 \%$ and decrease it for females by $18.5 \%$. This resides in males' inclination to have more maneuvers and risky behaviors in wider roads.

The multi-vehicle crashes and colliding with fixed objects raise the possibility of injury accidents among males while for females it increases the possibility of damage accidents. It is also concluded that overturning accidents are more severe among males. This finding corroborates earlier observations by $(21,48,53,72)$ for all types of drivers. For males, headson and angle crashes tend to be more severe while sideswipe accidents resulted mostly in damages. Conversely, collision type factors were statistically insignificant in all cases for females.

\section{Conclusions}

This study is aimed to identify important characteristics affecting severe crashes with particular focus on the comparison between male and female drivers. Few studies have focused on revealing the distinctive features of males and females crash severity. For this purpose this study has estimated two models using disaggregate road accident data for 2009 in Iranian City of Tehran. Since the severity included 2 levels (fatal/injury or damage only), the binary logit models have been developed.

Findings of this study reveal that factors affecting crash severity are different among male and female drivers which could be due to their different driving patterns. This issue alerts authorities and safety professionals to take these differences into consideration before taking any action or making any policy for safety improvement.

The factors which were found to have a significant effect on increasing crash severity among males are: driver's age (young and old drivers), illiterate driver, unnecessary haste, violation of driving laws, speeding, diversion to left, occurring during weekends, at night, at intersections, while clear and foggy weather, low traffic congestion, narrow and wide roads, multivehicle and rollover crashes, collision with fixed objects and collision type (head on and angle).

Comparing with middle age drivers, young and old drivers (both males and females) caused more severe car accidents. By taking into consideration the extremely adverse effect of elderliness on crash severity for both genders, higher emphasis is required for the safety of this age group of both sexes. Young females had greater effect on increasing the crash severity, comparing to young male drivers. This could be due to the fact that females in Iran usually have less driving opportunities as compared to males, due to their poor self-confident and underestimating of their abilities imposed by their families which consequently limits their driving experience (73). Consequently, they experience more severe crashes.

Illiteracy considerably increases probability of severe accidents for both genders. More attention on driver training courses for illiterate applicants (males and females) may be one of the ways of attenuating severity of car accidents by this group of drivers. Interesting results were obtained regarding driver errors affecting the crash severity. Lack of driving experience and loss of vehicle control among females were found as factors that increased crash severity. In addition, 
surveys of the driver errors affecting the crash severity among males and females revealed that males tend to drive more carelessly without fully obeying the laws. Apparently, males adventurous and aggressive traits and their tendency to drive in higher speeds comparing with females could be the reason for these findings. Özkan and Lajunen (74) assumed that being a skillful driver is a manly trait while being a careful driver is a womanly trait. Unfortunately, lack of driving experience among females, their tendency to be more careful in driving and their commitment to driving laws such as fastening seat belt are held up to ridicule by male drivers in Iran (75). This can reduce such commitments from females, leading to speeding among them in near future. Higher law reinforcements by the authorities could be effective in increasing respect for law and safety level. Mechanical defects of vehicles increase severity of car accident among female drivers due to outdated and worn vehicles along with the lack of enough knowledge about the vehicle mechanical issues among females. Thus, it is recommended that more training regarding mechanical defects of vehicle and diagnosing them must be offered for female driving applicants. Expectedly, such training adds the chance of diagnosing probable malfunctions by female drivers and lessens crash severity consequently. Also, it was noticed that during peak hours and at night, the severity of accidents were decreased and increased, respectively, for both genders.

In spite of males, clear weather decreases the probability of severe accident among females, while rainy weather increases such accidents among them. Both male and female drivers experience severe accidents in light traffic, while, in comparison, males are more probable to suffer severe car accident in such situations. In highways, female drivers show an increase in severity of accidents. It seems that females skill of controlling the vehicle in high speed is lower than that of males. In addition, dangerous driving by Iranian males and driving at higher-than-normal speed in slow lanes in highways causes trouble for female drivers (75).

Accident in intersections increases the severity among females as well as male drivers. Low road width (up to $18 \mathrm{~m}$ ) intensifies the severity and wider road ( $25 \mathrm{~m}$ and above) lessens the severity among females. Changing lane by male drivers on wide roads increases the likelihood for occurring severe crashes among them, while females do not tend to change their course of driving due to their instinctive cautious. Factors like multivehicle crashes and hitting fixed object lead to decreased crash severity among females.

Investigating the driving and behavioral differences between males and females in suburban roads and comparing with those in urban streets might be a recommended subject for future studies. In addition, studying the possible difference of driving patterns in different urban locations (e.g. intersections and highways) can be another important topic. Finally, comparing differences among how driver's gender affects crash severity in developed and developing countries, is suggested as future study.

\section{References}

[1] WHO. A Decade of Action for Road Safety: A Brief Planning Document. World Health Organization, 2013.

[2] M. R. Ahadi, and H. Razi-Ardakani, "Estimating the Cost of Road Traffic Accidents in Iran Using Human Capital Method," International Journal of Transportation Engineereing, vol. 2, no. 3, pp. 163-178, 2015.

[3] R. Hejazi, M. N. Shamsudin, A. Radam, K. A. Rahim, Z. Z. Ibrahim and S. Yazdani, "Estimation of Traffic Accident Costs: A Prompted Model," International Journal of Injury Control and Safety Promotion, vol. 20, no. 2, pp. 152-157, 2013.

[4] D. L. Massie, K. L. Campbell and A. F. Williams, "Traffic Accident Involvement Rates by Driver Age and Gender," Accident Analysis and Prevention, vol. 27, no. 1, pp. 73-87, 1995.

[5] A. E. Drummond, and E.-Y. Yeo, The Risk of Driver Crash Involvement as a Function of Driver Age. Monash University, Accident Research Centre, 1992.

[6] J. Broughton, Casualty Rates among Car Occupants, 1976-1986. Transport and Road Research Laboratory, 1990.

[7] J. Downes, Road Casualty Rates and Costs for the Former Metropolitan Counties. 0266-5247. 1988.

[8] G. Grime, Handbook of Road Safety Research. 1987.

[9] J. A. Bhatti, A. Constant, L. R. Salmi, M. Chiron, S. Lafont, M. Zins and E. Lagarde, "Impact of Retirement on Risky Driving Behavior and Attitudes Towards Road Safety among a Large Cohort of French Drivers (the Gazel Cohort)," Scandinavian Journal of Work, Environment and Health, vol. 34, no. 4, pp. 307-315, 2008.

[10] Q. Wu, G. Zhang, C. Chen, R. Tarefder, H. Wang and H. Wei "Heterogeneous Impacts of Gender-Interpreted Contributing Factors on Driver Injury Severities in Single-Vehicle Rollover Crashes," Accident Analysis \& Prevention, vol. 94, pp. 28-34, 2016. 
[11] N. Amarasingha, and S. Dissanayake, "Gender Differences of Young Drivers on Injury Severity Outcome of Highway Crashes," Journal of safety research, vol. 49, no., 2014, pp. 113. e111-120.

[12] J.-K. Kim, G. F. Ulfarsson, S. Kim and V. N. Shankar, "Driver-Injury Severity in Single-Vehicle Crashes in California: A Mixed Logit Analysis of Heterogeneity Due to Age and Gender," Accident Analysis \& Prevention, vol. 50, pp. 1073-1081, 2013.

[13] D. L. Massie, P. E. Green and K. L. Campbell, "Crash Involvement Rates by Driver Gender and the Role of Average Annual Mileage," Accident Analysis \& Prevention, vol. 29, no. 5, pp. 675-685, 1997.

[14] G. Li, S. P. Baker, J. A. Langlois and G. D. Kelen, "Are Female Drivers Safer? An Application of the Decomposition Method," Epidemiology, vol. 9, no. 4, pp. 379-384, 1998.

[15] M. Karacasu, and A. Er, "An Analysis on Distribution of Traffic Faults in Accidents, Based on Driver's Age and Gender: Eskisehir Case," Procedia-Social and Behavioral Sciences, vol. 20, pp. 776-785, 2011.

[16] Bener, A. and D. Crundall, "Role of Gender and Driver Behaviour in Road Traffic Crashes," International Journal of Crashworthiness, vol. 13, no. 3, pp. 331-336, 2008.

[17] A. H. Al-Balbissi, "Role of Gender in Road Accidents," Traffic Injury Prevention, vol. 4, no. 1, pp. 64-73, 2003.

[18] E. Santamariña-Rubio, K. Pérez, M. Olabarria and A. M. Novoa, "Gender Differences in Road Traffic Injury Rate Using Time Travelled as a Measure of Exposure," Accident Analysis \& Prevention, vol. 65, pp. 1-7, 2014.

[19] S. Laapotti, E. Keskinen and S. Rajalin, "Comparison of Young Male and Female Drivers' Attitude and SelfReported Traffic Behaviour in Finland in 1978 and 2001," Journal of Safety Research, vol. 34, no. 5, pp. 579-587, 2003.

[20] R. Arvin, M. Khademi and H. Razi-Ardakani, "Study on Mobile Phone Use While Driving in a Sample of Iranian Drivers," International Journal of Injury Control and Safety Promotion.

[21] G. F. Ulfarsson, and F. L. Mannering, "Differences in Male and Female Injury Severities in Sport-Utility Vehicle, Minivan, Pickup and Passenger Car Accidents," Accident Analysis and Prevention, vol. 36, no. 2, pp. 135-147, 2004.

[22] J. Bergdahl, and M. R. Norris, "Sex Differences in Single Vehicle Fatal Crashes: A Research Note," The Social Science Journal, vol. 39, no. 2, pp. 287-293, 2002.

[23] T. E. Keeler, "Highway Safety, Economic Behavior, and Driving Environment," The American Economic Review, vol. 84, no. 3, pp. 684-693, 1994.

[24] N. Harré, J. Field and B. Kirkwood, "Gender Differences and Areas of Common Concern in the Driving Behaviors and Attitudes of Adolescents," Journal of Safety Research, vol. 27, no. 3, pp. 163-173, 1996.

[25] S. Laapotti, and E. Keskinen, "Differences in Fatal Loss-of-Control Accidents between Young Male and Female Drivers," Accident Analysis and Prevention, vol. 30, no. 4, pp. 435-442, 1998.

[26] S. Laapotti, and E. Keskinen, "Has the Difference in Accident Patterns between Male and Female Drivers Changed between 1984 and 2000?," Accident Analysis and Prevention, vol. 36, no. 4, pp. 577-584, 2004.

[27] H.-L. Chang, and T.-H. Yeh, "Motorcyclist Accident Involvement by Age, Gender, and Risky Behaviors in Taipei, Taiwan," Transportation Research Part F: Traffic Psychology and Behaviour, vol. 10, no. 2, pp. 109-122, 2007.

[28] J. Hersch, "Smoking, Seat Belts, and Other Risky Consumer Decisions: Differences by Gender and Race," Managerial and Decision Economics, vol. 17, no. 5, pp. 471-481, 1996.

[29] D. Yagil, "Gender and Age-Related Differences in Attitudes toward Traffic Laws and Traffic Violations," Transportation Research Part F: Traffic Psychology and Behaviour, vol. 1, no. 2, pp. 123-135, 1998.

[30] T. Kelley-Baker, and E. Romano, "Female Involvement in Us Nonfatal Crashes under a Three-Level Hierarchical Crash Model," Accident Analysis \& Prevention, vol. 42, no. 6, pp. 2007-2012, 2010.

[31] T. Petzoldt, N. Bär and J. F. Krems, Gender Effects on Lane Change Test (Lct) Performance. Big Sky MT, 2009, pp. 90-96.

[32] A. Nyberg, and N. P. Gregersen, "Practicing for and Performance on Drivers License Tests in Relation to Gender Differences in Crash Involvement among Novice Drivers," Journal of Safety Research, vol. 38, no. 1, pp. 71-80, 2007.

[33] P. F. Lourens, J. A. Vissers and M. Jessurun, "Annual Mileage, Driving Violations, and Accident Involvement in Relation to Drivers' Sex, Age, and Level of Education," Accident Analysis \& Prevention, vol. 31, no. 5, pp. 593-597, 1999.

[34] D. R. Tavris, E. M. Kuhn and P. M. Layde, "Age and Gender Patterns in Motor Vehicle Crash Injuries: Importance of Type of Crash and Occupant Role," Accident Analysis \& Prevention, vol. 33, no. 2, pp. 167-172, 2001. 
[35] A. F. Williams, and V. I. Shabanova, "Responsibility of Drivers, by Age and Gender, for Motor-Vehicle Crash Deaths," Journal of Safety Research, vol. 34, no. 5, pp. 527-531, 2003.

[36] C. Bingham, and J. Ehsani, "The Relative Odds of Involvement in Seven Crash Configurations by Driver Age and Sex," Journal of Adolescent Health, vol. 51, no. 5, pp. 484-490, 2012.

[37] M. J. Bauer, G. Adler, M. A. Kuskowski and S. Rottunda, "The Influence of Age and Gender on the Driving Patterns of Older Adults," Journal of Women and Aging, vol. 15, no. 4, pp. 3-16, 2003.

[38] S. Islam, and F. Mannering, "Driver Aging and Its Effect on Male and Female Single-Vehicle Accident Injuries: Some Additional Evidence," Journal of Safety Research, vol. 37, no. 3, pp. 267-276, 2006.

[39] K. Obeng, "Gender Differences in Injury Severity Risks in Crashes at Signalized Intersections," Accident Analysis and Prevention, vol. 43, no. 4, pp. 1521-1531, 2011.

[40] K. Train, Discrete Choice Methods with Simulation. Cambridge University Press, 2003.

[41] C. F. Manski, "The Structure of Random Utility Models," Theory and decision, Vol. 8, No. 3, 1977, pp. $229-254$.

[42] D. A. Hensher, J. M. Rose and W. H. Greene, Applied Choice Analysis: A Primer. Cambridge university press, 2005.

[43] M. H. Kutner, C. Nachtsheim and J. Neter, Applied Linear Regression Models, 2004.

[44] S. P. Washington, M. G. Karlaftis and F. L. Mannering Statistical and Econometric Methods for Transportation Data Analysis. Chapman and Hall/CRC, 2003.

[40] C. Stata, Stata Statistical Software: Release 12.0. College Station, TX: Stata Corp, 2011.

[45] L. Y. Chang, and F. Mannering, "Analysis of Injury Severity and Vehicle Occupancy in Truck- and Non-TruckInvolved Accidents," Accident Analysis and Prevention, vol. 31, no. 5, pp. 579-592, 1999.

[45] K. Haleem, and M. Abdel-Aty, "Examining Traffic Crash Injury Severity at Unsignalized Intersections," Journal of Safety Research, vol. 41, no. 4, pp. 347-357, 2010.

[46] R. Paleti, N. Eluru and C. R. Bhat, "Examining the Influence of Aggressive Driving Behavior on Driver Injury Severity in Traffic Crashes," Accident Analysis and Prevention, vol. 42, no. 6, pp. 1839-1854, 2010.

[48] T. A. Rana, S. Sikder and A. R. Pinjari, "Copula-Based Method for Addressing Endogeneity in Models of Severity of Traffic Crash Injuries: Application to Two-Vehicle Crashes," Transportation Research Record, vol. 2147, no. 1, 2010, pp. 75-87.

[49] P. C. Anastasopoulos, and F. L. Mannering, "An Empirical Assessment of Fixed and Random Parameter Logit Models Using Crash- and Non-Crash-Specific Injury Data," Accident Analysis and Prevention, vol. 43, no. 3, pp. 1140-1147, 2011.

[50] K. Haleem, and A. Gan, "Identifying Traditional and Nontraditional Predictors of Crash Injury Severity on Major Urban Roadways," Traffic Injury Prevention, vol. 12, no. 3, pp. 223-234, 2011.

[51] P. F. Hanley, and N. Sikka, "Bias Caused by Self-Reporting Distraction and Its Impact on Crash Estimates," Accident Analysis and Prevention, 2012.

[52] Y. Xie, K. Zhao and N. Huynh, "Analysis of Driver Injury Severity in Rural Single-Vehicle Crashes," Accident Analysis and Prevention, vol. 47, pp. 36-44, 2012.

[53] K. M. Kockelman, and Y. J. Kweon, "Driver Injury Severity: An Application of Ordered Probit Models," Accident Analysis and Prevention, vol. 34, no. 3, pp. 313-321, 2002.

[54] R. Elvik, "Speed and Road Safety: Synthesis of Evidence from Evaluation Studies," Transportation Research Record, vol. 1908, pp. 59-69, 2005.

[55] J. M. Holdridge, V. N. Shankar and G. F. Ulfarsson, "The Crash Severity Impacts of Fixed Roadside Objects," Journal of Safety Research, vol. 36, no. 2, pp. 139-147, 2005.

[56] T.Yamamoto, J. Hashiji and V. N. Shankar, "Underreporting in Traffic Accident Data, Bias in Parameters and the Structure of Injury Severity Models," Accident Analysis and Prevention, vol. 40, no. 4, pp. 1320-1329, 2008.

[57] S. M. Rifaat, and R. Tay, "Effects of Street Patterns on Injury Risks in Two-Vehicle Crashes," Transportation Research Record, vol. 2102, pp. 61-67, 2009.

[58] W. H. Schneider, P. T. Savolainen and K. Zimmerman, "Driver Injury Severity Resulting from Single-Vehicle Crashes Along Horizontal Curves on Rural Two-Lane Highways," Transportation Research Record, vol. 2102, pp. 85-92, 2009.

[59] S. Altwaijri, M. A. Quddus and A. L. Bristow, Factors Affecting the Severity of Traffic Crashes in Riyadh City. Washington, D.C., 2011. 
[61] M. Shams, and V. Rahimi-Movaghar, "Risky Driving Behaviors in Tehran, Iran," Traffic Injury Prevention, vol. 10, no. 1, pp. 91-94, 2009.

[62] L. Y. Chang, and F. L. Mannering, "Predicting Vehicle Occupancies from Accident Data: An Accident Severity Approach," Transportation Research Record, vol. 1635, pp. 93-104, 1998.

[63] J. Zhang, J. Lindsay, K. Clarke, G. Robbins and Y. Mao, "Factors Affecting the Severity of Motor Vehicle Traffic Crashes Involving Elderly Drivers in Ontario," Accident Analysis and Prevention, vol. 32, no. 1, pp. 117-125, 2000.

[64] R. C. Gray, M. A. Quddus and A. Evans, "Injury Severity Analysis of Accidents Involving Young Male Drivers in Great Britain," Journal of Safety Research, vol. 39, no. 5, pp. 483-495, 2008.

[65] M. A. Quddus, C. Wang and S. G. Ison, "Road Traffic Congestion and Crash Severity: Econometric Analysis Using Ordered Response Models," Journal of Transportation Engineering, vol. 136, no. 5, pp. 424-435, 2010.

[66] Z. Wang, H. Chen and J. J. Lu, "Exploring Impacts of Factors Contributing to Injury Severity at Freeway Diverge Areas," Transportation Research Record, vol. 2102, pp. 43-52, 2009.

[67] C. Peek-Asa, C. Britton, T. Young, M. Pawlovich and S. Falb, "Teenage Driver Crash Incidence and Factors Influencing Crash Injury by Rurality," Journal of Safety Research, vol. 41, no. 6, pp. 487-492, 2010.

[68] M. Abdel-Aty, A. A. Ekram, H. Huang and K. Choi, "A Study on Crashes Related to Visibility Obstruction Due to Fog and Smoke," Accident Analysis and Prevention, vol. 43, no. 5, pp. 1730-1737, 2011.

[69] Z. Li, P. Liu, W. Wang and C. Xu, "Using Support Vector Machine Models for Crash Injury Severity Analysis," Accident Analysis and Prevention, vol. 45, pp. 478-486, 2012.

[70] Y. Xie, Y. Zhang and F. Liang, "Crash Injury Severity Analysis Using Bayesian Ordered Probit Models," Journal of Transportation Engineering, vol. 135, no. 1, pp. 18-25, 2009.

[71] N. V. Malyshkina, and F. L. Mannering, "Empirical Assessment of the Impact of Highway Design Exceptions on the Frequency and Severity of Vehicle Accidents," Accident Analysis and Prevention, vol. 42, no. 1, pp. 131-139, 2010.

[72] W. Hu, and E. T. Donnell, "Median Barrier Crash Severity: Some New Insights," Accident Analysis and Prevention, vol. 42, no. 6, pp. 1697-1704, 2010.

[73] A. Esmaeli, Women and Men Diffrences in Driving. Police University Publisher, 2011.

[74] T. Özkan, and T. Lajunen, "What Causes the Differences in Driving between Young Men and Women? The Effects of Gender Roles and Sex on Young Drivers' Driving Behaviour and Self-Assessment of Skills," Transportation Research Part F: Traffic Psychology and Behaviour, vol. 9, no. 4, pp. 269-277, 2006.

[75] A. Soori, Correction the Offenders Driving Behavior. Police University Publisher, 2012. 